Mitologías presidenciales. Discurso y legitimidad de las experiencias latinoamericanas

Florencia Daniela Rispolo

Question, Vol. 1, N. 56, e016, octubre-diciembre 2017. ISSN 1669-6581

http://perio.unlp.edu.ar/ojs/index.php/question/article/view/4381

IICom- FPyCS | Universidad Nacional de La Plata

La Plata | Buenos Aires | Argentina

Recibido: 29-09-2017 Aceptado: 12-10-2017

Cita sugerida: Rispolo, F. (2017). Mitologías presidenciales. Discurso y legitimidad de las experiencias

latinoamericanas. Question, 1(56), e016. doi: https://doi.org/10.24215/16696581e016

\title{
Mitologías presidenciales. Discurso y legitimidad de las experiencias latinoamericanas
}

\author{
Presidential mythologies. Speech and legitimacy of Latin-American experiences
}

Florencia Daniela Rispolo

Instituto de Humanidades y Ciencias Sociales del Litoral;

Universidad Nacional del Litoral/ Consejo Nacional

de Investigaciones Científicas y Técnicas (Argentina)

rispoloflorencia@gmail.com

\section{Resumen}

La presente reseña fue realizada en base a la lectura y el análisis del libro Comunicación gubernamental en acción. Narrativas presidenciales y mitos de gobierno, publicado en marzo de 2016. El mismo ha sido editado por Mario Riorda y Omar Rincón para la colección Cuadernos de Comunicación, de la editorial Biblos. La obra es un compendio de artículos que abordan la noción de mitos políticos como recurso privilegiado para construir legitimidad, en los gobiernos de América Latina. De este modo, el texto nos muestra un abordaje teórico sobre las 
concepciones en torno al mito político y un análisis empírico de algunos gobiernos latinoamericanos.

Palabras clave: mito político; medios de comunicación; acción política.

Abstract

This paper was realized accordingto the reading and analysis of the book Comunicación gubernamental en acción. Narrativas presidenciales y mitos de gobierno published in march 2016 and edited by Mario Riorda and Omar Rincón in the Cuadernos de Comunicación collection, by Biblos. The article is a compilation of papers whichhave the assumption that construction of political myths is a privileged resource to build legitimacy in the governments of Latin America. In this way, we can findtheoretical appreciations about the concept of political myth and subsequently, different cases studies of the different Latin American governments.

Keysword: political myth; mass media; political action.

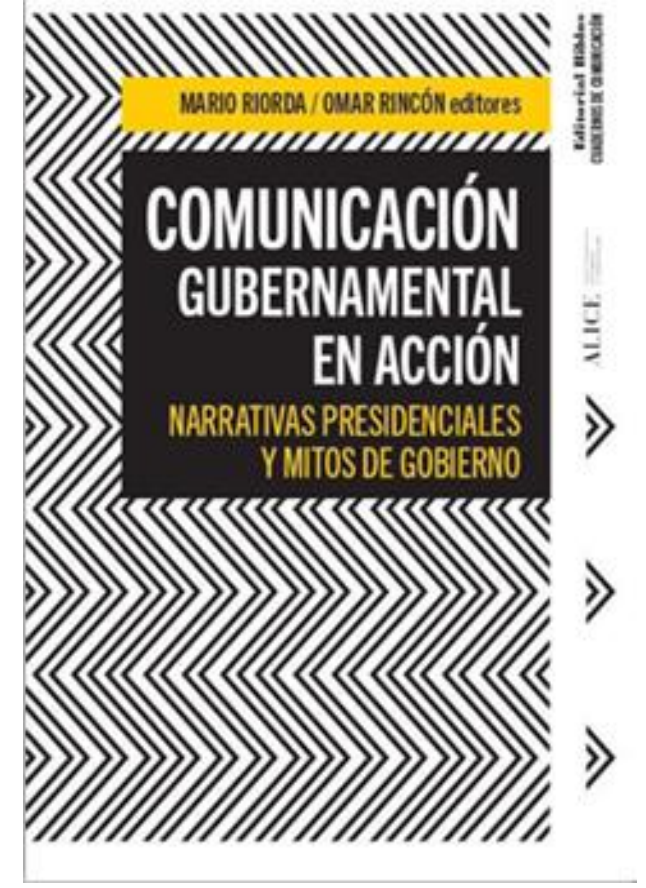

Título: Comunicación gubernamental en acción. Narrativas presidenciales y mitos de gobierno.

Editores: Mario Riorda y Omar Rincón

Año: 2016

Colección: Cuadernos de comunicación

Editorial: Biblos

ISBN: 9789876914468

Número de páginas: 284 
"Los medios no son el poder, apenas son su cheerleader. El poder está en otra parte: en el relato y el mito político" (Riorda y Rincón, 2016: 11). Estas son las primeras líneas del libro Comunicación gubernamental en acción. Narrativas presidenciales y mitos de gobierno, editado por Mario Riorda y Omar Rincón. El mismo presenta un compendio de artículos que abordan, de manera detallada, la construcción de mitos políticos como recurso privilegiado para construir legitimidad en los gobiernos de Latinoamérica. El libro describe un recorrido en torno al análisis teórico y empírico del concepto de mito político y su aplicación en las narrativas presidenciales. En este sentido, la obra dialoga con algunas de las producciones que estos autores han realizado sobre comunicación: "Hacia un modelo de comunicación gubernamental para el consenso" (2006) de Riorda; Comunicación gubernamental 360 (2013) de Elizalde y Riorda y Medios, democracia y poder. Una mirada comparada desde Colombia, Ecuador, Venezuela y Argentina (2011) de Rettberg y Rincón. Aborda la tesis de la centralidad de la comunicación en la construcción de legitimidad de los gobiernos latinos.

De este modo, la obra se estructura en tres partes: introducción, primera parte o pre-textos y una segunda parte, titulada mitologías nacionales. Las dos primeras secciones proveen información de corte teórico y desarrollan los conceptos básicos que atravesarán todos los artículos compilados; en tanto que, en la segunda sección, se realiza un análisis de la construcción efectiva de la idea de mito que se sucede en los gobiernos de Argentina, Bolivia, Brasil, Chile, Colombia, Ecuador, México, Perú, República Dominicana, Uruguay y Venezuela. Los primeros artículos que aparecen en la compilación buscan desmitificar la idea sobre la relevancia de los medios de comunicación en el mundo de la política, dejando al descubierto que las necesidades, expectativas y saberes de la ciudadanía no se satisfacen con estrategias de comunicación, sino con políticas concretas. Esto no significa que deba prescindirse de la comunicación de gobierno; por el contrario, las acciones, obras y programas que se llevan a cabo deben estar organizados alrededor de un relato sobre el modelo de país, de un mito de gobierno.

En el mito, las dimensiones del discurso y la acción política convergen para generar consenso y vincular al ciudadano con el gobierno. En otras palabras, esta es la herramienta que posibilita la apropiación por parte de la ciudadanía del proyecto general que propone el gobierno. Así, los presidentes utilizan al mito para crear universos de sentido común, mantener el consenso social y construir legitimidad en torno a la realidad que se plantea como objetivo de gobierno. Esta es la idea vertebradora que recorre los distintos capítulos del libro.

La comunicación es fundamental, ya que permite instalar el modelo e incorporar a los ciudadanos a un horizonte común que posibilita percibir el futuro en las claves que el gobierno propone. Sin embargo, se debe recordar que el mito debe ser coherente con las promesas realizadas durante la etapa electoral y con las acciones gubernamentales efectivamente llevadas a cabo. Así, el objetivo del mito es lograr desde el campo simbólico "una serie de 
propuestas discursivas que hagan ver la realidad de una determinada manera a la mayor cantidad de personas" (Riorda y Roggero, 2016: 55).

Consecuentemente, a lo largo de la primera parte del libro podemos encontrar artículos como "El mito político y su aplicación en la comunicación de gobierno" de Mario Riorda y Caroline Ávila, que retoma los abordajes teóricos que se han realizado en torno a la idea de mito y los elementos claves para el aprovechamiento de este recurso en la comunicación de gobierno. En "Y el mito se hizo carne: organización y preservación del mito de gobierno", Mario Riorda y Marcos Roggero realizan una descripción pormenorizada del proceso deconstrucción, preservación y continuidad del mito. Allí se menciona la existencia de tres momentos fundamentales: el primero, propio de los momentos de campaña, caracterizado por el carisma del líder y la efervescencia política; un segundo momento, en donde se rutiniza el carisma y entran en juego las organizaciones, la burocracia y las políticas públicas; y finalmente, el momento en donde se institucionaliza o tradicionaliza el mito. El último de los capítulos de esta sección está a cargo de Omar Rincón: "El gobernante es el medio: mitologías presidenciales". Aquí se plantea una interesante tesis, a partir de la cual se sostiene que en la actualidad el éxito del mito depende de que el gobernante sea el medio; es decir, el presidente debe convertirse en el instrumento para transmitir el mensaje. De esta forma, se analizan las narrativas presidenciales de los gobiernos latinoamericanos que dominan el mercado de la opinión pública e imponen sus relatos de hegemonía política.

Enmarcada en la idea de utilidad aplicativa, la segunda parte del libro se compone de análisis de casos de los distintos países de América Latina. De este modo, encontramos artículos que indagan sobre la construcción del discurso kirchnerista en la Argentina: "Matices de un relato con pocos matices: comunicación gubernamental en los gobiernos kirchneristas" y "El candidato es el proyecto" a cargo de Damián Fernández Pedemonte y Rocío Annunziata, respectivamente. Asimismo, aparecen los mitos basados en revoluciones o revueltas populares como los de Hugo Chávez en Venezuela, Evo Morales en Bolivia o el PRI en México; y el mito de la nación o la patria para los gobiernos de Lula y Eloy Alfaro. Mitos exitosos, como el de "José Mujica, el presidente más pobre del mundo: narrativas presidenciales y mitos de gobierno", o los de Álvaro Uribe y Juan Manuel Santos basados en la noción de guerra y paz de Colombia. Mitos fallidos, como los de Perú desde la llegada de Fujimori al poder, o Chile, con los gobiernos de Pinera y la segunda administración de Bachelet. Y finalmente casos paradigmáticos, como el de Republica Dominicana, en donde la popularidad del presidente Medina y la aprobación de su gestión de gobierno resultan inversamente proporcionales.

En pocas palabras, el lector de este libro encontrará un interesante compendio de artículos que abordarán de manera cohesionada el fenómeno de la construcción de legitimidad en los gobiernos latinoamericanos. Ofreciendo, de este modo, un mapa conceptual sobre el mito 
político y los desempeños presidenciales de los gobiernos recientes de Argentina, Bolivia, Brasil, Chile, Colombia, Ecuador, México, Perú, República Dominicana, Uruguay y Venezuela.

\section{Bibliografía}

Elizalde, L. y Riorda, M. (Eds.) (2006). Comunicación gubernamental 360. Buenos Aires, Argentina: La Crujía.

Riorda, M. y Roggero, M. (2016). Y el mito se hizo carne: organización y preservación del mito de gobierno. En M. Riorda y O. Rincón. (Eds.) Comunicación gubernamental en acción. Narrativas presidenciales y mitos de gobierno (pp. 53-72). Buenos Aires, Argentina: Biblos.

Riorda, M. (1 de septiembre de 2006). Hacia un modelo de comunicación gubernamental para el consenso. Revista del foro iberoamericano sobre estrategias de comunicación, II(4).

Rettberg, A. y Rincón, O. (Coord.) (2011). Medios, democracia y poder. Una mirada comparada desde Colombia, Ecuador, Venezuela y Argentina. Bogotá, Colombia: Universidad de los Andes. 